\title{
PENGARUH PEMILIHAN LOKASI DAGANG TERHADAP VISIBILITAS PEDAGANG KAKI LIMA
}

\author{
Alfanadi Agung Setiyawan \\ Prodi. Magister Arsitektur, Departemen Arsitektur Fakultas Teknik, Universitas Diponegoro \\ alfanadisetiyawan@gmail.com
}

\section{Suzanna Ratih Sari}

Prodi. Magister Arsitektur, Departemen Arsitektur Fakultas Teknik, Universitas Diponegoro ratihsaris@yahoo.com

\section{Agung Budi Sardjono}

Prodi. Magister Arsitektur, Departemen Arsitektur Fakultas Teknik, Universitas Diponegoro agungbsardjono@gmail.com

\begin{abstract}
Abstrak
Trotoar adalah salah satu bentuk ruang terbuka yang menunjang segala kegiatan pada skala kawasan. Berfungsi sebagai elemen transportasi perkotaan yakni wadah bagi pejalan kaki dengan tidak melupakan pendukung aktivitas yang memanfaatkan keberadaan pejalan kaki di trotoar. Keberadaan pendukung aktivitas yang salah satunya adalah pedagang kaki lima (PKL) memiliki hubungan timbal balik dengan pejalan kaki. Interaksi jual beli yang terjadi antara PKL dan pejalan kaki terkadang menimbulkan masalah, salah satunya adalah tuntutan kebutuhan ruang. Banyaknya PKL yang menuntut kebutuhan ruang berbanding terbalik dengan dimensi ruang yang ada, sehingga menyebabkan kesesakan (crowding) antar pengguna trotoar. Melupakan fungsi utamanya, trotoar didominasi dan dipersepsikan menjadi area komersial oleh PKL. Penelitian ini bertujuan untuk mencari keterkaitan antara persepsi atribut visibilitas yang ditunjukkan dengan bagaimana mereka berperilaku saat menata lapak pada latar seting trotoar koridor Pandanaran, Semarang. Mulai dari PKL datang, menata lapak, orientasi memasang spanduk, hingga selesai. Pemilihan lokasi dan penataan lapak di trotoar diduga didasari pada kekuatan propertis pada setting dan adanya tuntutan dari atribut visibilitas serta atribut lain yang mendukungnya. Metode Person Centered Mapping dan kuesioner akan digunakan untuk memperoleh data rekaman perilaku maupun data statistik PKL dalam berdagang di trotoar. Data yang didapatkan kemudian dianalisa menggunakan metode analisis statistik deskriptif.
\end{abstract}

Kata-kata Kunci: Perilaku, Atribut, Visibilitas, Pedagang Kaki Lima, Trotoar

\section{THE EFFECT OF TRADE LOCATION SELECTION TOWARDS STREET VENDOR'S VISIBILITY}

\begin{abstract}
The Sidewalk is one of the open space forms that support all activities on a regional scale. As an element of urban transportation, it serves to accommodate pedestrians by not forgetting supporters of activities that utilize the presence of pedestrians on the sidewalk. The existence of
\end{abstract}


activity supports, in which one of them is street vendors, has a reciprocal relationship with pedestrians. Buy-and-sell interactions that occur between street vendors and pedestrians sometimes cause problems, such as the demand for space needs. The large number of street vendors who demand space is inversely proportional to the existing spatial dimensions, thus causing crowding among sidewalk users. Sidewalks, whose primary function is forgotten, are dominated and perceived to be commercial areas by street vendors. This study aims to look for the relationship between perceptions of visibility's attribute shown by how they behave when arranging shanties in the setting of the Pandanaran corridor sidewalk, Semarang. Starting from the street vendors coming, arranging shanties, banner orientation, until the finish. The selection of location of stalls on the sidewalk is allegedly based on the strength of the property in the setting and the existence of demands for visibility attribute and other attributes which were supported. The Person-Centered Mapping method and questionnaire will be used to obtain behavioral record data as well as street vendor's statistical data in trading on the sidewalk. The data collected were then analyzed using descriptive statistical analysis methods.

Keywords: Behavior, Attributes, Visibility, Street Vendors, Sidewalk

\section{Pendahuluan}

Jalur pejalan kaki atau trotoar adalah jalur yang khusus diperuntukkan bagi pejalan kaki yang berfungsi untuk sirkulasi, berjalan kaki, demo menyuarakan pendapat, bahkan dibeberapa tempat telah didesain fungsi tambahan yakni parkir dan berjualan. Perencanaan jalur pejalan kaki yang baik biasanya mengikuti koridor jalan yang telah ada sehingga mampu mewadahi kegiatan yang berlangsung pada koridor tersebut. Menurut Grigg, Trotoar atau pedestrian ways termasuk kedalam pengelompokan prasarana road group atau kelompok jalan (Grigg, 1988). Prasarana ini digunakan oleh pejalan kaki, dimana kedudukannya didalam perancangan kota adalah bersinergi dengan elemen transportasi lain seperti jalan kendaraan, jembatan penyeberangan, halte, dan lainnya. Menurut teori Shirvani (1985) mengenai elemen pembentuk kota, trotoar juga merupakan pendukung aktivitas (activity support) dimana trotoar menunjang perkembangan dan efektivitas segala kegiatan di kota.

Seiring berjalannya waktu, serta tuntutan, trotoar tidak lagi sepenuhnya memberikan rasa aman dan nyaman kepada penggunanya. Sering terjadi konflik perebutan ruang gerak antara pejalan kaki dan pengguna lainnya, khususnya pedagang kaki lima (PKL) atau "hawkers" yang menjajakan barang dan jasa di trotoar yang notabene adalah tempat umum(McGee \& Yeung, 1977). Meskipun regulasi yang ada telah disahkan dan berulangkali pula kegiatan penataan trotoar dilakukan, akan tetapi Pedagang Kaki Lima tetap kembali berdagang pada trotoar yang sama. Kasus pada koridor jalan Pandanaran kota Semarang adalah salah satunya.

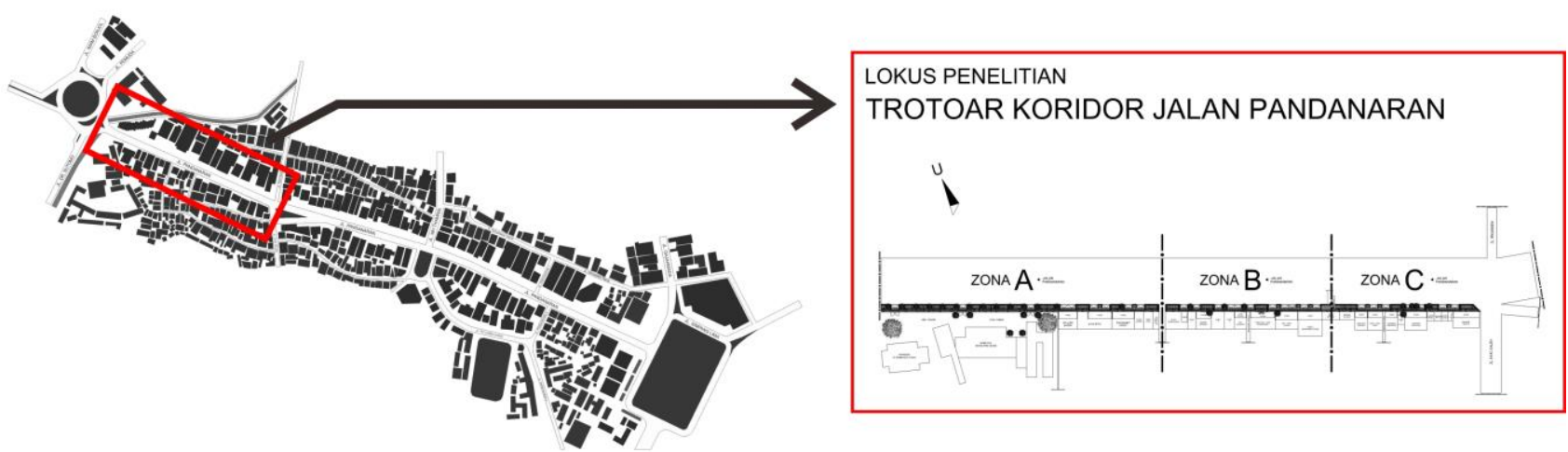

Gambar 1. Lokus Penelitian pada Penggal Jalan Pandanaran Sumber: Dokumentasi Penulis, 2020 
Jalan Pandanaran merupakan salah satu jalan protokol yang cukup padat (lihat Gambar 1). Merupakan salah satu dari tiga koridor jalan yang memperoleh julukan dari Pemerintah Kota Semarang sebagai "segitiga emas" yang mewadahi segala pusat bisnis dan perdagangan, dimana fungsi trotoarnya pun ikut dipengaruhi kegiatan disekitarnya. Pada awalnya kawasan ini hanya terdiri dari bangunan perkantoran dengan beberapa bangunan komersial seperti restoran dan pusat oleh oleh. Kemudian seiring berjalannya waktu, kawasan ini berkembang dan diikuti oleh merebaknya ratusan PKL disepanjang koridor jalan Pandanaran. Informasi terkini, hanya segelintir pedagang yang masih berdagang dan hanya berdagang didekat toko formal. Sehingga karakter dagangannya berkaitan erat antara toko formal dan PKL (Widjajanti, 2009).

Kondisi fisik trotoar yang sempit menyebabkan PKL yang memaksakan berdagang menjadi saling berhimpit. Berdimensi hanya 3,5 meter belum termasuk street furniture dan prasarana umum lain, pedagang tetap memposisikan dirinya berdagang di trotoar. Dengan harapan agar dagangan terlihat oleh pengendara dan pejalan kaki yang lewat sehingga laris, PKL memposisikan lapak ditepian jalan. Bagi PKL yang tidak mendapatkan lapak ditepian jalan, terpaksa berdagang pada muka toko, terhalang PKL lain yang berada didepannya maupun terhalang street furniture yang ada seperti pohon dan jembatan. (lihat Gambar 2). Sehingga membutuhkan usaha tambahan agar dagangan tetap terlihat, seperti orientasi spanduk dan memposisikan objek lapak pada area yang terlihat.

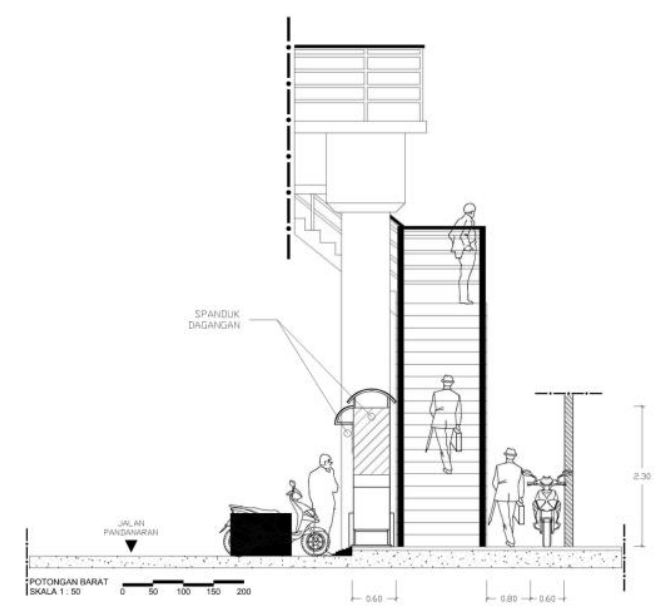

Gambar 2. Lapak PKL pada Setting Trotoar Koridor Jalan Pandanaran Sumber: Dokumentasi Penulis, 2020

Pengamatan lapangan dilakukan pada 10 November 2019 yang kemudian mendapatkan keterbaruan data dari pengamatan lapangan tanggal 3 dan 4 Desember 2019, diperoleh data sejumlah 33 PKL yang aktif berdagang dengan rentang waktu yang beragam. Untuk mempermudah pengamatan dan analisa, koridor jalan Pandanaran dibagi menjadi tiga zona yakni A, B, dan C (lihat Gambar 3). Pembagian ini berdasarkan pada persebaran PKL pada trotoar koridor jalan Pandanaran, dimana masing - masing zona memiliki batas fisik berupa jalan lingkungan atau jembatan penyeberangan. 


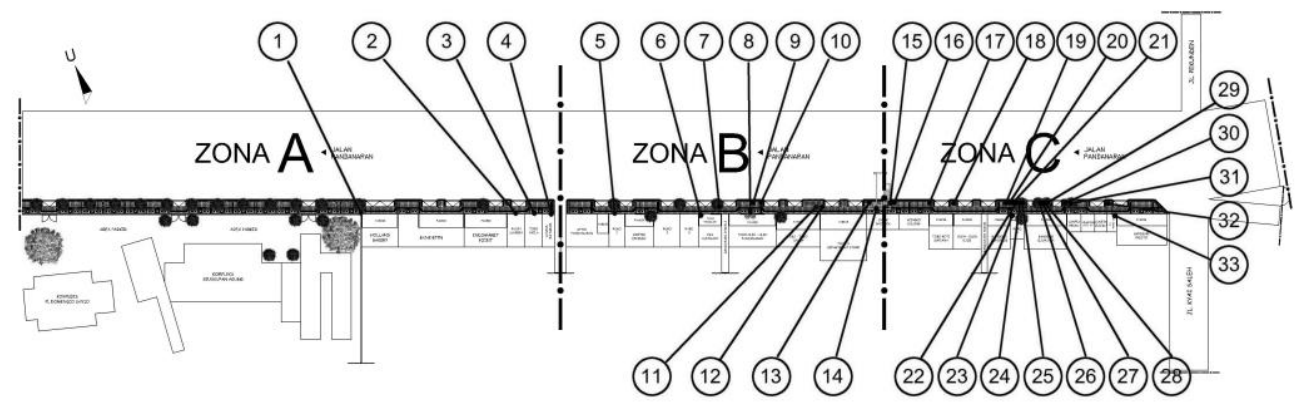

Gambar 3. Persebaran PKL Koridor Jalan Pandanaran

Sumber: Dokumentasi Penulis, 2020

\section{Hubungan Persepsi dan Perilaku}

Sebelum manusia berperilaku atau bersikap, terlebih dahulu muncul persepsi yang diawali dari penginderaan terhadap suatu rangsangan (Wardianto, Budihardjo, \& Prianto, 2012). Rangsangan ini hadir dari susunan benda yang selanjutnya dikenal dengan istilah propertis yang muncul di lingkungan sekitarnya. Pada teori Bell (2001) tentang Eclectic Model, persepsi yang tercipta dari proses penginderaan ini akan menghasilkan reaksi berupa Sikap (lihat Gambar 4).

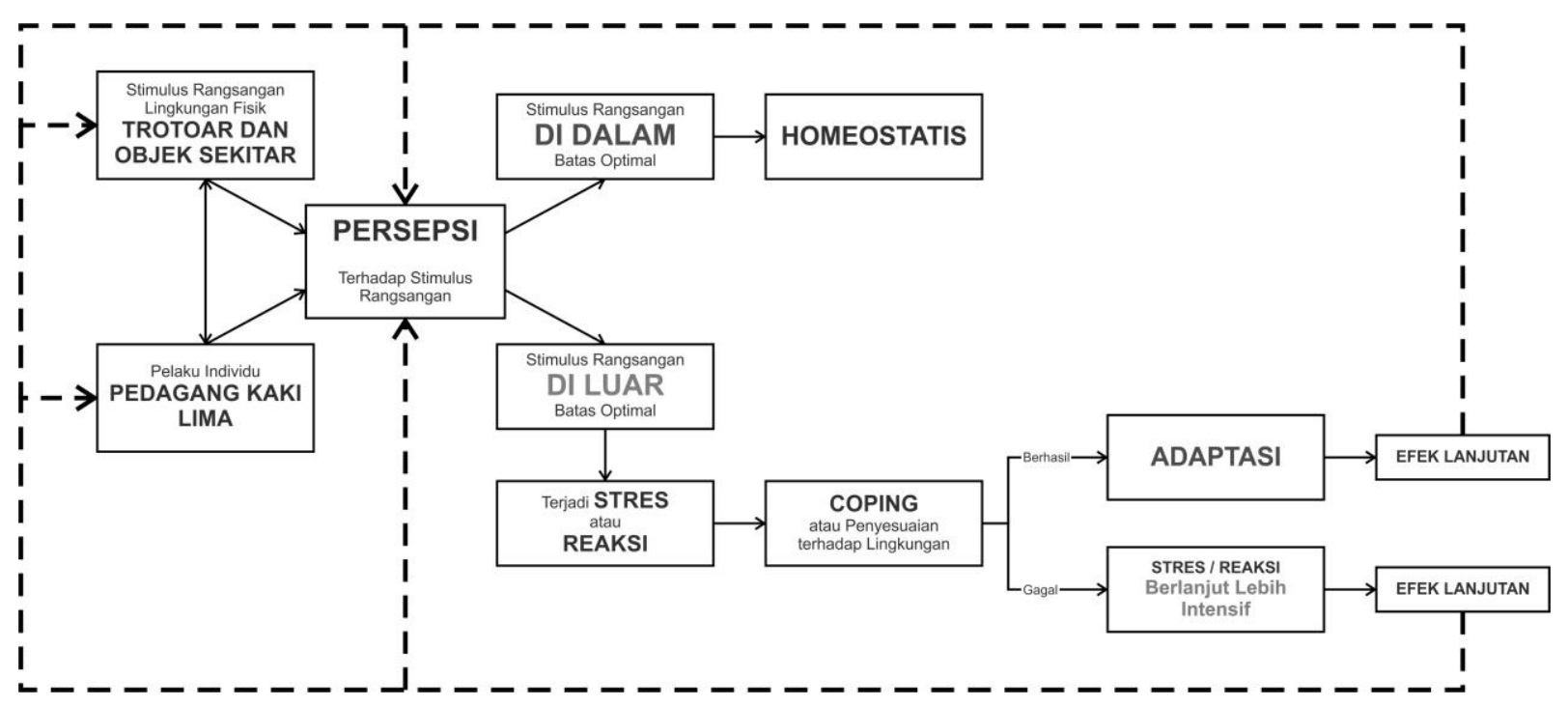

Gambar 4. Eclectic Model, Hubungan Persepsi dengan Perilaku

Sumber: (Bell, Fisher, \& Loomis, 2001)

Hubungan manusia dengan lingkungan diawali dengan kontak fisik individu dengan objek propertis sekitar, pada penelitian ini dapat dianalogikan PKL berinteraksi dengan gerobak dan street furniture yang dijadikan patokan lapak pada trotoar. Objek propertis muncul dengan sifat kemanfaatan bagi PKL, sementara individu (PKL) muncul dengan sifat individualnya. Interaksi individu dengan lingkungan tersebut menghasilkan persepsi. Apabila persepsi masih berada didalam batas optimal, maka dapat diartikan dalam posisi Homeostatis atau seimbang. Keadaan ini harus dipertahankan karena memberikan kenyamanan bagi individu tersebut. Apabila persepsi berada diluar batas optimal, maka akan memunculkan reaksi sehingga individu melakukan coping atau adaptasi dengan lingkungan. Ada dua kemungkinan yakni keberhasilan (berupa adaptasi) dan kegagalan (stres berkepanjangan).

Sifat individual disini diartikan faktor internal dari diri masing - masing orang berupa motif, minat, tujuan minat, dan harapan (Atkinson, 1983). Lebih lanjut diterangkan oleh Lewin (1951, 
dalam Azwar, 2002) dimana sifat individual yang saling berinteraksi kemudian bersinergi dengan lingkungan akan menentukan Sikap atau Perilaku individu tersebut (Azwar, 2002).

\section{Propertis dan Setting}

Sifat Propertis adalah karakteristik intrinsik, bermakna sebuah sifat yang menentukan suatu hal menjadi apa adanya (Archea, 1977). Propertis selalu hadir kepada siapa saja dan dimana saja, bahkan kepeda mereka yang tidak memahami sehingga menafsirkan propertis dengan tafsiran lain. Warna barang, kepadatan, kekuatan tarik atau tekan, kesimetrian, keberadaan yang tidak semestinya, dan visi binokular adalah beberapa contoh sifat propertis. Sifat - sifat itulah yang memberikan batasan visual berdasarkan aktifitas manusia didalam sebuah ruang, karena pada dasarnya propertis adalah bagian dari lingkungan fisik / setting.

Sementara setting menurut Rapoport didalam Haryadi (2010), setting merupakan wadah ruang fisik dimana kebiasaan hidup sehari - hari seseorang tertuang. Penggunaan istilah seting lebih tepat digunakan dibandingkan dengan ruang, karena definisi ruang biasanya lebih bersifat spasial. Sementara kenyataannya ruang terintegrasi dengan manusia dengan segala aktivitasnya didalam kurun waktu tertentu (Haryadi \& Setiawan, 2010). Sehingga diputuskan istilah setting lebih tepat digunakan dibandingkan dengan istilah ruang.

\section{Atribut}

Serupa dengan teori Bell mengenai Eclectic Model, Weisman (1981) dengan teori Model Sistem Perilaku Lingkungan mengemukakan bahwa fenomena perilaku merupakan bentuk interaksi manusia (baik berupa individu atau organisasi) dengan setting lingkungan fisiknya (lihat Gambar 5).

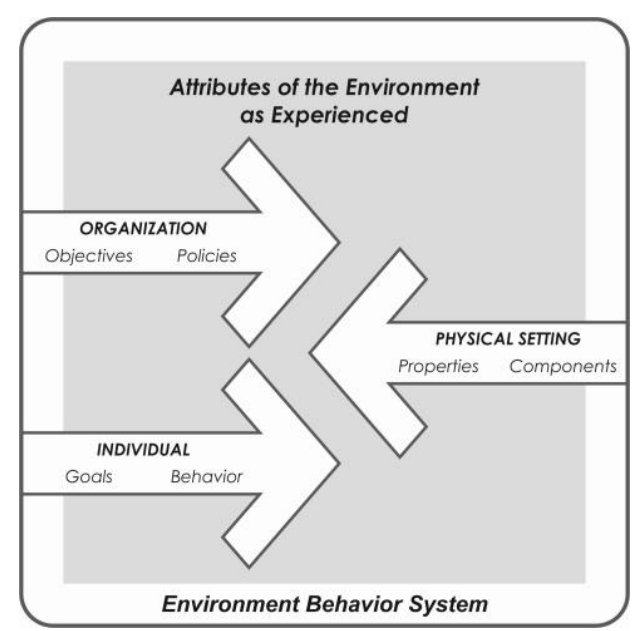

Gambar 5. Model Sistem Perilaku Lingkungan

Sumber: (Weisman, 1981)

Dari interaksi manusia dengan lingkungannya muncul istilah Atribut sebagai kualitas lingkungan yang dirasakan sebagai pengalaman manusia. Terdapat enam atribut menurut Weisman (1981) yakni sosiabilitas, kesesakan, keamanan, kenyamanan, aksesibilitas, dan visibilitas. Pengembangan lain oleh Windley \& Scheidt (1980) dalam Weisman menghasilkan dua belas atribut yakni :

a. Sosialitas (sociality), kemahiran manusia untuk melakukan kontak antar sesama dalam sebuah lingkungan.

b. Kesesakan (crowdedness), tingkat densitas / kesesakan yang diterima dalam lingkungan.

c. Kontrol (control), kondisi saat lingkungan memberikan batasan teritorial ruang untuk mewujudkan rasa aman (safety dan security). 
d. Kenyamanan (comfortability), keadaan lingkungan yang sesuai dengan pancaindera dan memfasilitasi kinerja.

e. Aksesibilitas (accessibility), kemudahan berpindah antar tempat.

f. Visibilitas (visibility), kemampuan untuk dapat melihat tanpa terhalang secara visual terhadap objek yang dituju (view to site) dan dari objek (view from site), berkaitan dengan jarak yang dirasakan oleh manusia.

g. Rangsangan Inderawi (sensory stimulation), intensitas stimulus atau rangsangan sebagai pengalaman yang diterima melalui berbagai media sensori.

h. Adaptabilitas (adaptability), kemampuan lingkungan untuk mengakomodasi pola atau perilaku baru.

i. Aktifitas (activity), perilaku yang dilakukan secara intens yang berlangsung di dalam lingkungan.

j. Privasi (privacy), kemampuan untuk memonitor informasi auditory maupun visual ke dan dari orang lain dengan tujuan agar tidak terganggu didalam sebuah lingkungan.

k. Legabilitas (legability), kemudahan bagi seseorang untuk mengenal elemen kunci dan hubungan spasialnya dalam sebuah lingkungan dalam tujuannya untuk menemukan arah jalan.

1. Makna (meaning), kemampuan lingkungan untuk menampilkan maksud keberadaannya baik makna individu atau makna budaya (Windley \& Scheidt-, 1980).

Tidak semua atribut harus muncul pada suatu setting. Pemilihan atribut itu sendiri harus dilihat relevansinya dengan setting lingkungan maupun perilaku individu disekitarnya. Untuk memilih dan menemukan atribut, terlebih dahulu menguraikan hubungan antara setting lingkungan fisik dengan perilaku manusia menggunakan metode Rekonseptualisasi Lingkungan Fisik (Archea, 1977). Rekonseptualisasi Lingkungan Fisik ini berupa pengamatan terhadap sifat lingkungan disertai dengan sketsa pemaknaan Behavioral Mapping, dapat berupa Person Centered Mapping maupun Place Centered Mapping.

\section{Hipotesa dan Pemilihan Atribut}

Persebaran PKL pada trotoar koridor jalan Pandanaran tidak merata (lihat Gambar 3). Pada zona A terdapat 4 PKL, zona B 10 PKL, dan zona C 19 PKL. Penumpukan PKL terjadi pada zona C dimana terdapat PKL yang berdagang tetapi terhalang oleh PKL lain serta street furniture yang ada. Temuan ini tidak sesuai dengan kaidah atribut Visibilitas dimana terdapat kemampuan untuk melihat tanpa terhalang baik itu view to site (pengendara / pejalan kaki melihat ke PKL) ataupun view from site (PKL dapat melihat pengendara / pejalan kaki). Ada dua kemungkinan :

a. PKL lebih mengutamakan atribut lain yang dirasa lebih diperlukan. Dapat berupa keberadaan tiang atau pohon dijadikan patokan (adaptabilitas) serta keberadaan pohon atau embatan penyeberangan orang dijadikan pernaungan (kenyamanan), sehingga visibilitas bukan atribut primer.

b. Meskipun tertutupi, ada upaya lain dari PKL untuk tetap terlihat. Dapat berupa penggunaan papan spanduk, separator, bendera atau objek dengan sifat propertis lain.

\section{Metode}

Penelitian ini terdiri dari empat langkah yaitu studi pendahuluan, pengembangan instrumen penelitian, pelaksanaan penelitian, serta analisa dan pemaknaan (lihat Gambar 6). Pada langkah pertama Studi Pendahuluan diawali dari menemukan fenomena serta latar belakang, perumusan masalah, studi literatur dan survey pendahuluan. Dilanjutkan merumuskan hipotesis dan identifikasi variabel. 


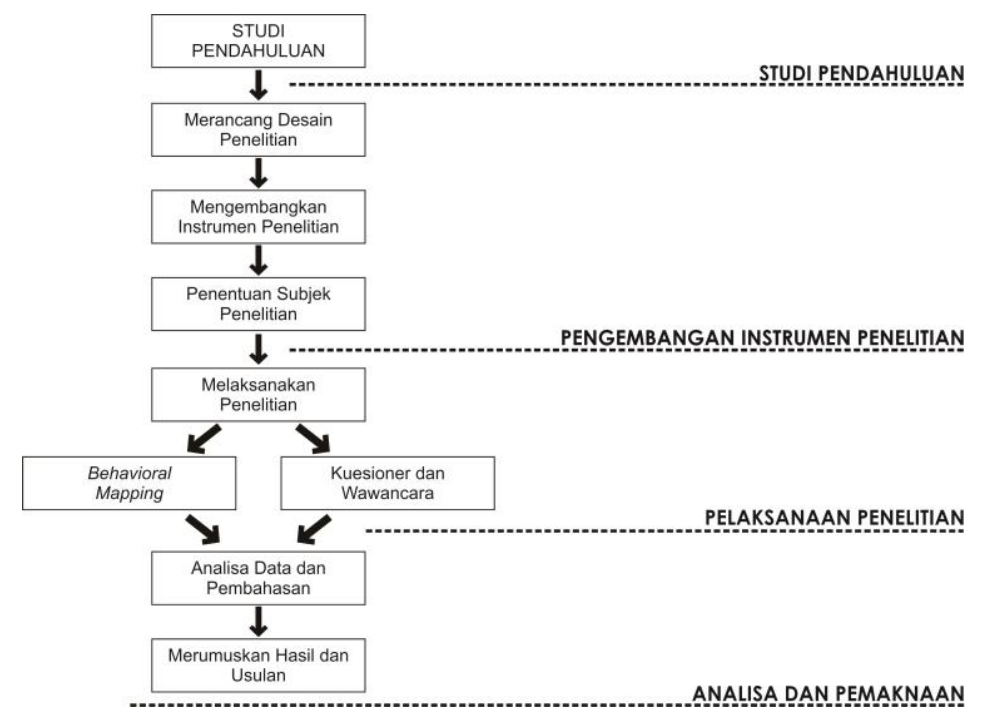

Gambar 6. Metode Penelitian

Sumber: Dokumentasi Penulis, 2019

Langkah kedua yakni Pengembangan Instrumen Penelitian. Diawali perancangan desain penelitian yang kemudian diikuti oleh pengembangan instrumen / variabel penelitian itu sendiri serta penentuan subjek penelitian. Karena menggunakan instrumen metode kuantitatif yakni kuesioner tertutup, maka ditentukan variabel bebas dan terikat. Variabel bebas berupa persepsi minat, tujuan, dan harapan (lihat Tabel 1). Sementara variabel terikat berupa atribut Visibilitas dan pendukungnya yakni Kenyamanan dan Adaptabilitas (lihat Tabel 2).

Tabel 1. Variabel Bebas

V. Bebas Indikator Tolok Ukur

\begin{tabular}{|c|c|c|c|}
\hline \multirow{6}{*}{$\begin{array}{c}\text { Persepsi PKL } \\
\text { terhadap } \\
\text { keberadaan } \\
\text { trotoar sebagai } \\
\text { prasarana pejalan } \\
\text { kaki }\end{array}$} & \multirow{2}{*}{ Minat } & 1. & $\begin{array}{l}\text { Sebagai Penghasilan Pokok (Pemilihan Lokasi dan Media Dagang } \\
\text { untuk Waktu yang Lama) }\end{array}$ \\
\hline & & 2. & $\begin{array}{l}\text { Sebagai Penghasilan Tambahan (Pemilihan Lokasi dan Media } \\
\text { Dagang untuk Sementara) }\end{array}$ \\
\hline & \multirow{2}{*}{ Tujuan minat } & 1. & $\begin{array}{l}\text { Pembeli Bisa Duduk / Berdiri, Sirkulasi Pejalan Kaki Lancar (Layout } \\
\text { Persegi / Persegi Panjang) }\end{array}$ \\
\hline & & 2. & $\begin{array}{l}\text { Pembeli Hanya Berdiri, Sirkulasi Pejalan Kaki Secukupnya (Layout } \\
\text { Letter L, T, U) }\end{array}$ \\
\hline & \multirow{2}{*}{ Harapan } & 1. & Dimensi dan desain trotoar perlu dirubah (adjusment) \\
\hline & & 2. & Dimensi dan desain trotoar dibiarkan apa adanya (adaptasi) \\
\hline
\end{tabular}

Sumber : Analisa Penulis, 2020

Tabel 2. Variabel Terikat

\begin{tabular}{|c|c|c|c|}
\hline V. Terikat & Indikator & & Tolok Ukur \\
\hline \multirow{2}{*}{$\begin{array}{l}\text { Atribut yang } \\
\text { Muncul dari } \\
\text { Setting } \\
\text { Trotoar }\end{array}$} & \multirow{2}{*}{ Visibilitas } & & View to site (lapak di tepi jalan, tidak terhalang) \\
\hline & & b. & View to site (lapak di muka toko, terhalang PKL lain) \\
\hline
\end{tabular}




\begin{tabular}{|c|c|c|c|}
\hline \multirow{10}{*}{$\begin{array}{c}\text { Koridor } \\
\text { Pandanaran } \\
\text { (Zona A, B, } \\
\text { dan C) }\end{array}$} & & a. & View from site (orientasi spanduk ke segala arah) \\
\hline & & b. & View from site (orientasi spanduk satu arah) \\
\hline & \multirow{4}{*}{ Kenyamanan } & a. & Bermanfaat (keberadaan JPO menjadi sarana memasang spanduk) \\
\hline & & b. & Tidak Bermanfaat (keberadaan JPO menutupi dagangan) \\
\hline & & a. & Bermanfaat (keberadaan Pohon menjadi pernaungan) \\
\hline & & b. & Tidak Bermanfaat (keberadaan pohon menutupi dagangan) \\
\hline & \multirow{4}{*}{ Adaptabilitas } & a. & Bermanfaat (tiang listrik menjadi patokan) \\
\hline & & b. & Tidak Bermanfaat (keberadaan tiang listrik menutupi dagangan) \\
\hline & & a. & Tidak bergeser (Keberadaan PKL lain menjadi patokan) \\
\hline & & b. & Bergeser (PKL lain menutupi dagangan) \\
\hline
\end{tabular}

\section{Sumber : Analisa Penulis, 2020}

Langkah ketiga yaitu Pelaksanaan Penelitian. Pada langkah ketiga ini metode yang digunakan menggunakan metode milik Kuantitatif yakni Kuesioner serta didukung metode Kualitatif berupa pemetaan perilaku atau behavioral mapping yang merupakan pemetaan berpola dan terjadi pada lokasi tertentu (B. Sommer \& Sommer, 1991). Behavioral Mapping yang digunakan berupa Person Centered Mapping yang menekankan pada pergerakan manusia pada periode waktu tertentu, dimana teknik ini berkaitan dengan tidak hanya satu tempat atau lokasi akan tetapi beberapa tempat / lokasi (Haryadi \& Setiawan, 2010). Pada teknik ini peneliti berhadapan dengan seseorang yang khusus diamati. Langkah-langkah yang dilakukan pada teknik ini adalah :

1. Menentukan jenis sampel person yang akan diamati (aktor / pengguna ruang secara individu).

2. Menentukan waktu pengamatan (pagi, siang, malam)

3. Mengamati aktivitas yang dilakukan dari masing-masing individu.

4. Mencatat aktivitas sampel yang diamati dalam matrix

5. Membuat alur sirkulasi sampel di area yang diamati mengetahui kemana orang itu pergi

Dalam pelaksanaannya menurut Michelson dan Reed dalam Laurens (2004), behavior mapping dibatasi oleh time budget. Memiliki tujuan untuk memperlihatkan individu dalam menggunakan waktu sebaik - baiknya (Laurens, 2004). Penelitian ini menerapkan time budget dengan rentang waktu 07.00 - 08.00, 12.00 - 13.00, dan 18.00 - 19.00 dengan memperkirakan waktu buka, jam puncak (peak hour), serta waktu tutup PKL.

Pada langkah terakhir yakni analisa dan pemaknaan, data yang didapatkan dianalisa menggunakan metode analisis statistik deskriptif yang kemudian diinterpretasi.

\section{Hasil dan Pembahasan \\ Data Analisa Persepsi PKL}

Persepsi PKL terhadap pemilihan lokasi dagang pada masing - masing zona (zona A, B, dan C) sebagai berikut (lihat Gambar 7). 


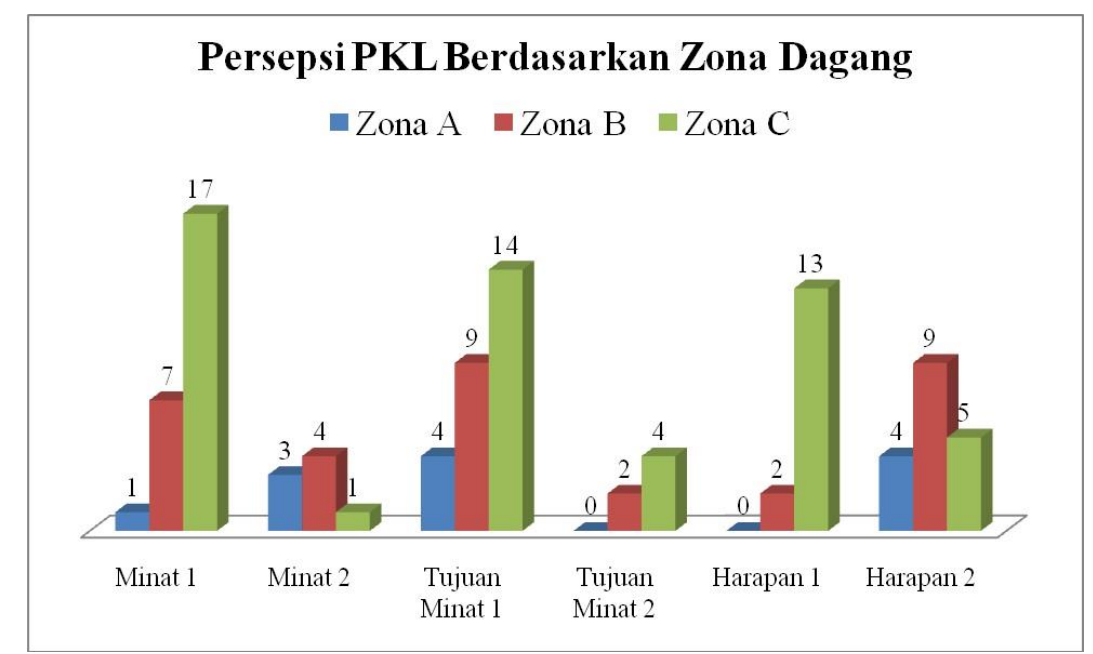

Gambar 7. Persepsi PKL dalam Memilih Zona Dagang Sumber: Analisa Penulis, 2020

Dari gambar histogram diatas, menunjukkan persepsi Minat 1 yakni berdagang sebagai penghasilan utama cenderung pada Zona $\mathrm{C}$ sejumlah $17 \mathrm{PKL}$ dengan presentase 52\% (N=33) sementara Minat 2 berdagang sebagai penghasilan tambahan didominasi pada Zona B sejumlah 4 PKL dengan presentase 3\% $(\mathrm{N}=33)$.

Untuk Tujuan Minat 1 berupa penataan lapak dengan lengkap didominasi Zona $\mathrm{C}$ sejumlah 14 PKL dengan presentase 42\% ( $\mathrm{N}=33)$ sementara Tujuan Minat 2 menata lapak dengan seadanya juga didominasi Zona $\mathrm{C}$ sejumlah 4 PKL dengan presentase $12 \%(\mathrm{~N}=33)$.

Mengenai Harapan 1 berupa perlunya ubahan dimensi dan desain trotoar didominasi oleh Zona C dengan jumlah 13 PKL presentase 39\% ( $\mathrm{N}=33)$, sementara Harapan 2 bahwa trotoar hanya perlu dipertahankan didominasi oleh Zona $\mathrm{B}$ dengan jumlah 9 PKL presentase $15 \%(\mathrm{~N}=33)$.

Hasil analisa dari data diatas, menunjukkan bahwa minat berdagang untuk penghasilan utama, tujuan minat penataan layout dengan lengkap serta harapan dimensi dan desain untuk diubah didominasi PKL yang berada di Zona C.

\section{Data dan Pembahasan Atribut PKL}

Data statistik yang dihasilkan dari atribut PKL yakni Visibilitas dan kemungkinan atribut yang mendukung visibilitas yakni kenyamanan dan adaptabilitas sebagai berikut (lihat Gambar 8). 


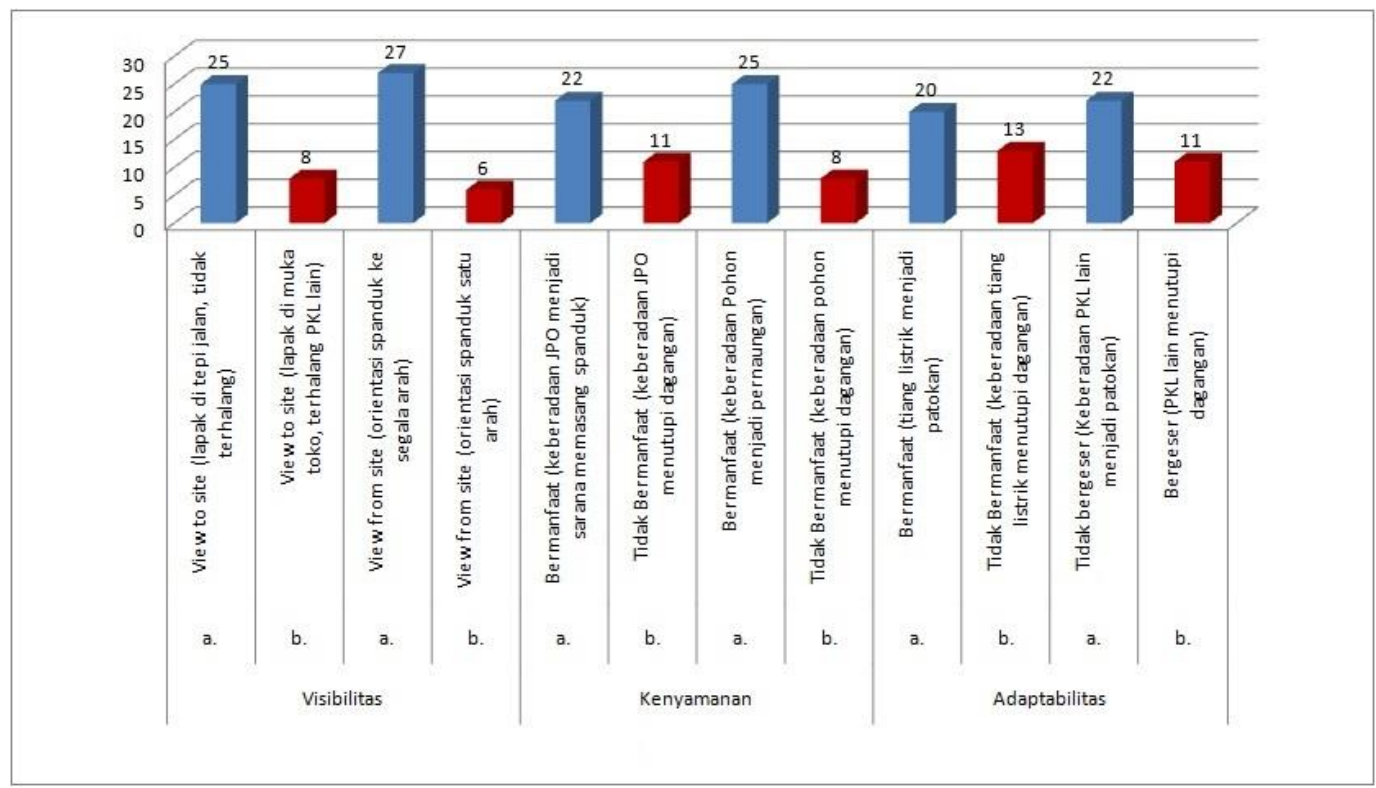

Gambar 8. Persepsi PKL dalam Memilih Zona Dagang Sumber: Analisa Penulis, 2020

\section{Atribut Visibilitas}

Grafik histogram diatas menunjukkan untuk atribut Visibilitas view to site Sub-atribut 1 berupa pemilihan lapak di pinggir jalan menunjukkan angka sejumlah 25 PKL, atau presentase $76 \%$ dari 33 PKL. Salah satu PKL yang memilih berdagang di pinggir jalan adalah pak Edi pedagang Lunpia yang berdagang pukul 07.30 - 19.30 pada Zona B (lihat Gambar 9).

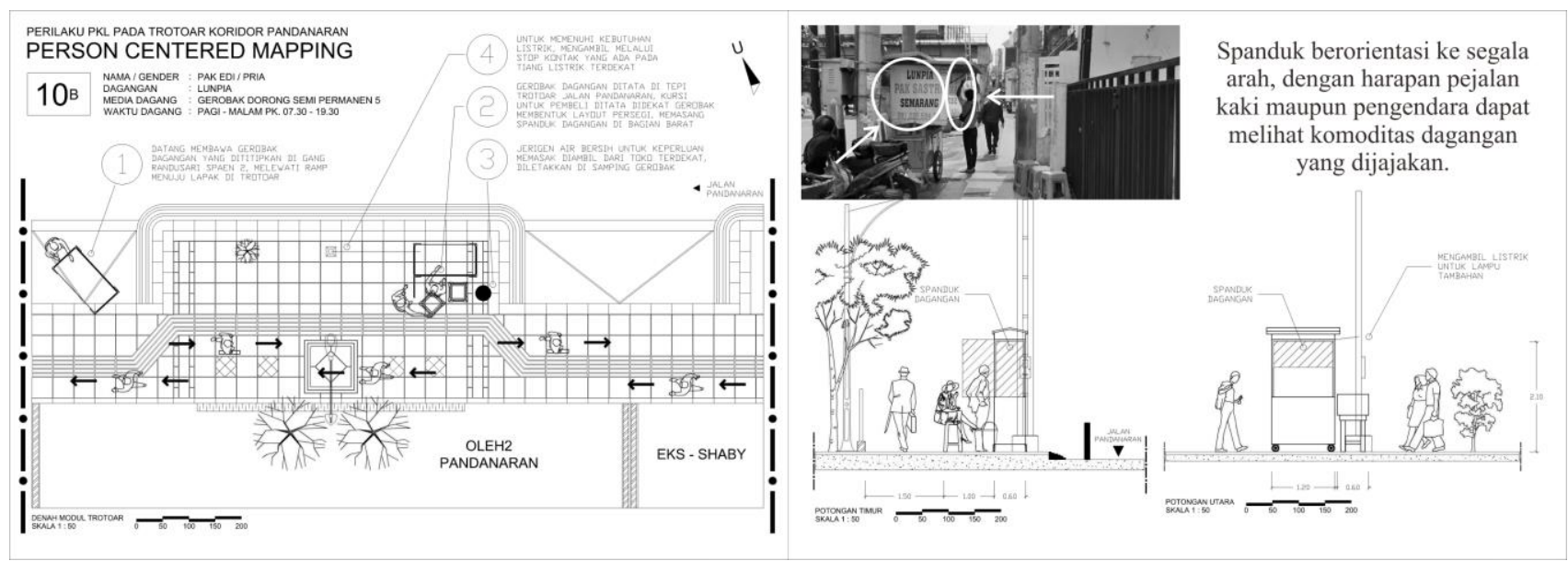

Gambar 9. Person Centered Mapping View to Site Sub-Atribut 1

Sumber: Analisa Penulis, 2020

Sementara Sub-atribut 2 berupa pemilihan lapak di muka toko menunjukkan angka sejumlah 8 PKL, atau presentase $24 \%$ dari 33 PKL. Salah satu PKL yang memilih berdagang di muka toko adalah pak Suparyono pedagang angkringan yang berdagang pukul 18.00 - 23.00 pada Zona A (lihat Gambar 10). 


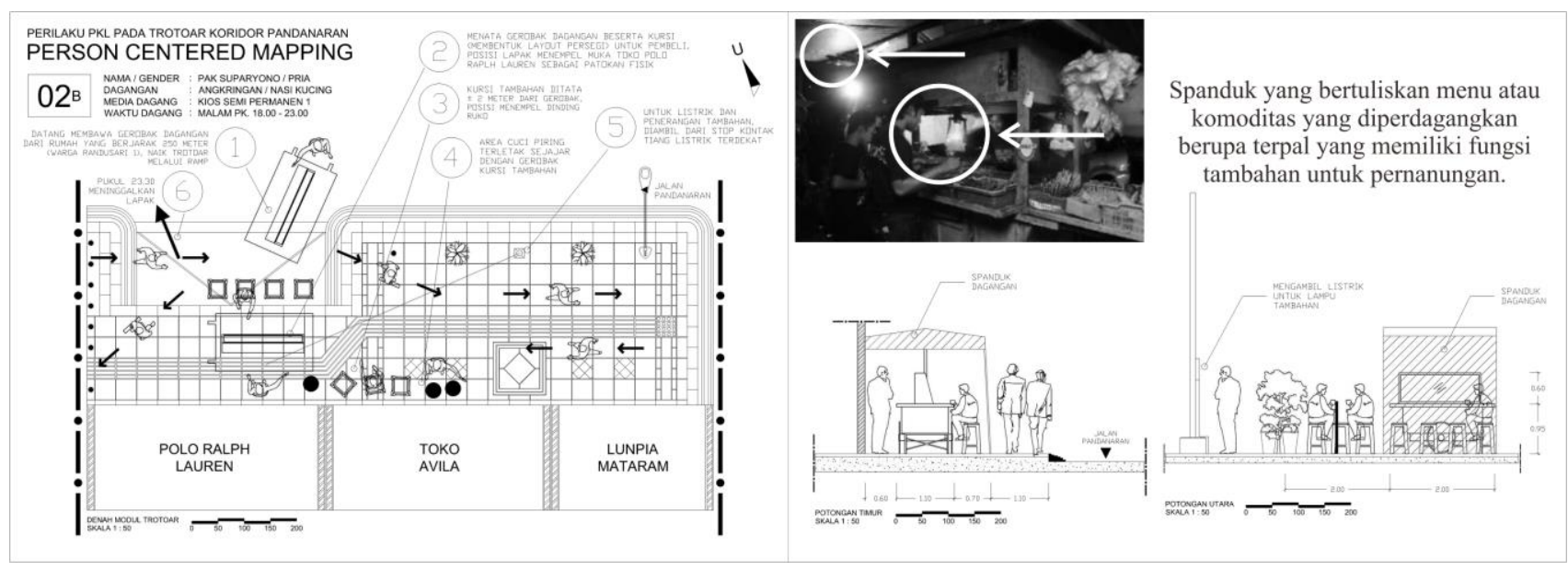

Gambar 10. Person Centered Mapping View to Site Sub-Atribut 2

Sumber: Analisa Penulis, 2020

Atribut Visibilitas view from site Sub-atribut 1 berupa orientasi spanduk ke segala arah menunjukkan angka sejumlah 27 PKL, atau presentase 82\% dari 33 PKL. Salah satu PKL dengan orientasi spanduk ke segala arah adalah pak Lies pedagang wingko babat yang berdagang pukul 10.00 - 22.00 pada Zona B (lihat Gambar 11).

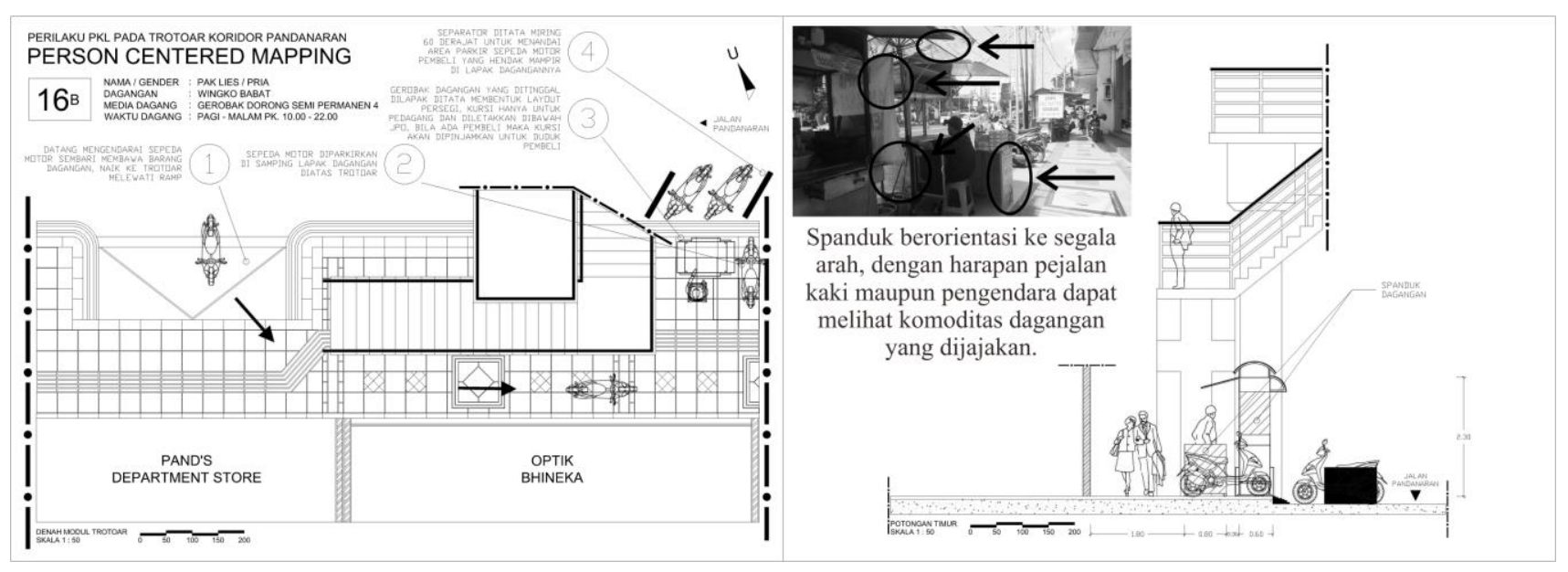

Gambar 11. Person Centered Mapping View from Site Sub-Atribut 1

Sumber: Analisa Penulis, 2020

Sementara Sub-atribut 2 berupa orientasi spanduk hanya satu arah menunjukkan angka sejumlah 6 PKL, atau presentase $18 \%$ dari 33 PKL. Salah satu dengan orientasi spanduk satu arah adalah bu Ayu pedagang kaos yang berdagang pukul 16.00 - 21.00 pada Zona B (lihat Gambar 12). 


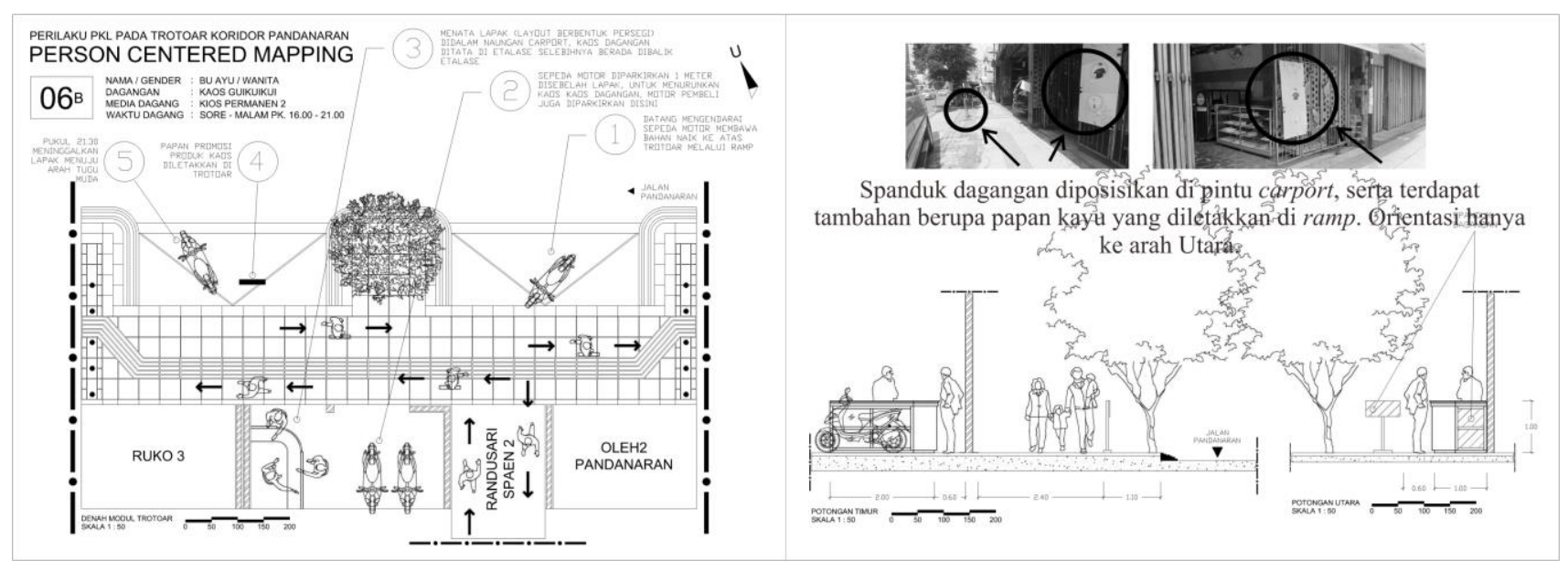

Gambar 12. Person Centered Mapping View from Site Sub-Atribut 2

Sumber: Analisa Penulis, 2020

\section{Atribut Kenyamanan}

Grafik histogram diatas menunjukkan untuk atribut Kenyamanan kebermanfaatan JPO Subatribut 1 berupa JPO dimanfaatkan untuk pemasangan spanduk menunjukkan angka sejumlah 22 PKL, atau presentase 67\% dari 33 PKL. Sementara Sub-atribut 2 berupa JPO menutupi dagangan menunjukkan angka sejumlah 11 PKL, atau presentase 33\% dari 33 PKL. Salah satu PKL yang memanfaatkan JPO untuk memasang spanduk adalah pak Lies pedagang wingko babat yang berdagang pukul $10.00-22.00$ pada Zona B (lihat Gambar 11).

Sementara atribut Kenyamanan kebermanfaatan Pohon Sub-atribut 1 berupa pohon untuk pernaungan menunjukkan angka sejumlah $25 \mathrm{PKL}$, atau presentase $76 \%$ dari 33 PKL. Sementara Sub-atribut 2 berupa pohon menutupi dagangan menunjukkan angka sejumlah 8 PKL, atau presentase $24 \%$ dari 33 PKL.

\section{Atribut Adaptabilitas}

Grafik histogram diatas menunjukkan untuk atribut Adaptabilitas kebermanfaatan Tiang Listrik Sub-atribut 1 berupa Tiang Listrik menjadi patokan menunjukkan angka sejumlah 20 PKL, atau presentase $61 \%$ dari 33 PKL. Sementara Sub-atribut 2 berupa Tiang Listrik menutupi dagangan menunjukkan angka sejumlah 13 PKL, atau presentase 39\% dari 33 PKL. Salah satu PKL yang memanfaatkan tiang listrik sebagai patokan sekaligus pemasangan spanduk dengan orientasi ke jalan adalah pak Suryadi pedagang tahu bakso yang berdagang pukul $09.00-21.00$ pada Zona C (lihat Gambar 13).

Sementara atribut Adaptabilitas keberadaan PKL Lain Sub-atribut 1 berupa PKL lain menjadi patokan menunjukkan angka sejumlah 22 PKL, atau presentase 67\% dari 33 PKL. Sementara Subatribut 2 berupa PKL lain menutupi dagangan menunjukkan angka sejumlah 11 PKL, atau presentase 33\% dari 33 PKL. Salah satu PKL yang memanfaatkan keberadaan PKL lain sebagai patokan, sementara spanduk berada di tepian jalan adalah pak Sumarno pedagang buah dan rokok yang berdagang pukul 06.00 - 13.00 pada Zona C (lihat Gambar 14). 


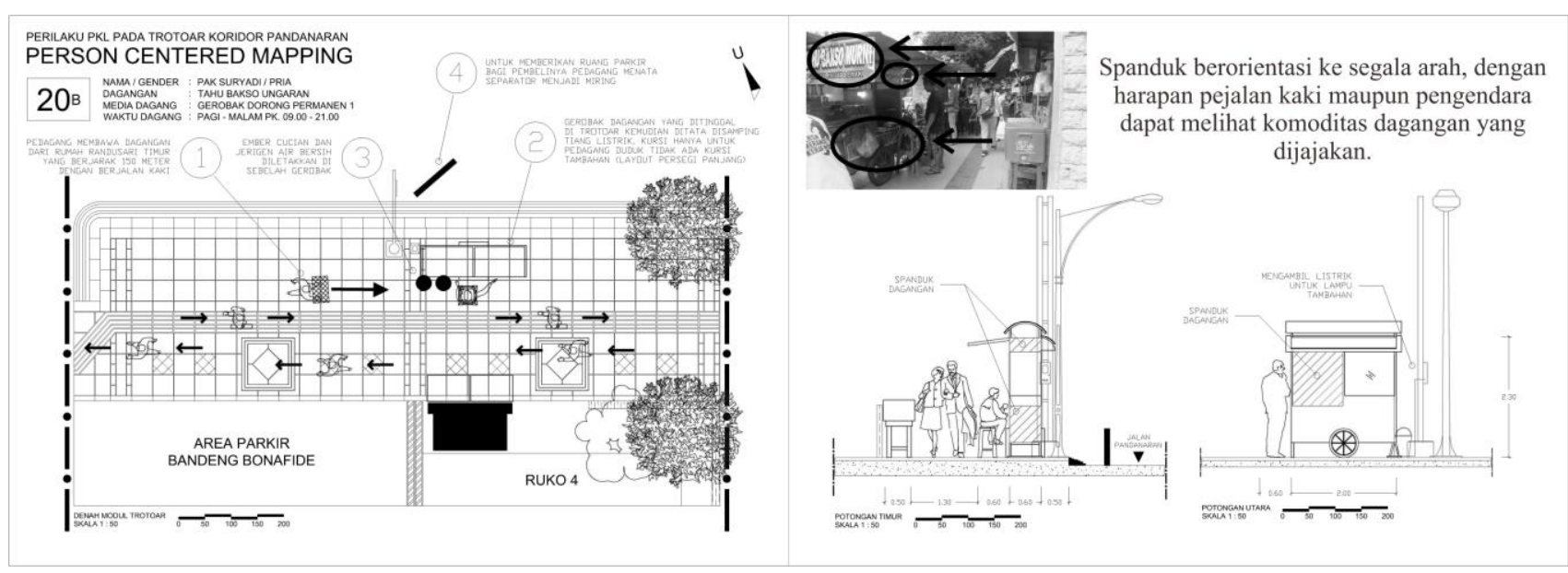

Gambar 13. Person Centered Mapping Adaptabilitas Manfaat Tiang Listrik

Sumber: Analisa Penulis, 2020

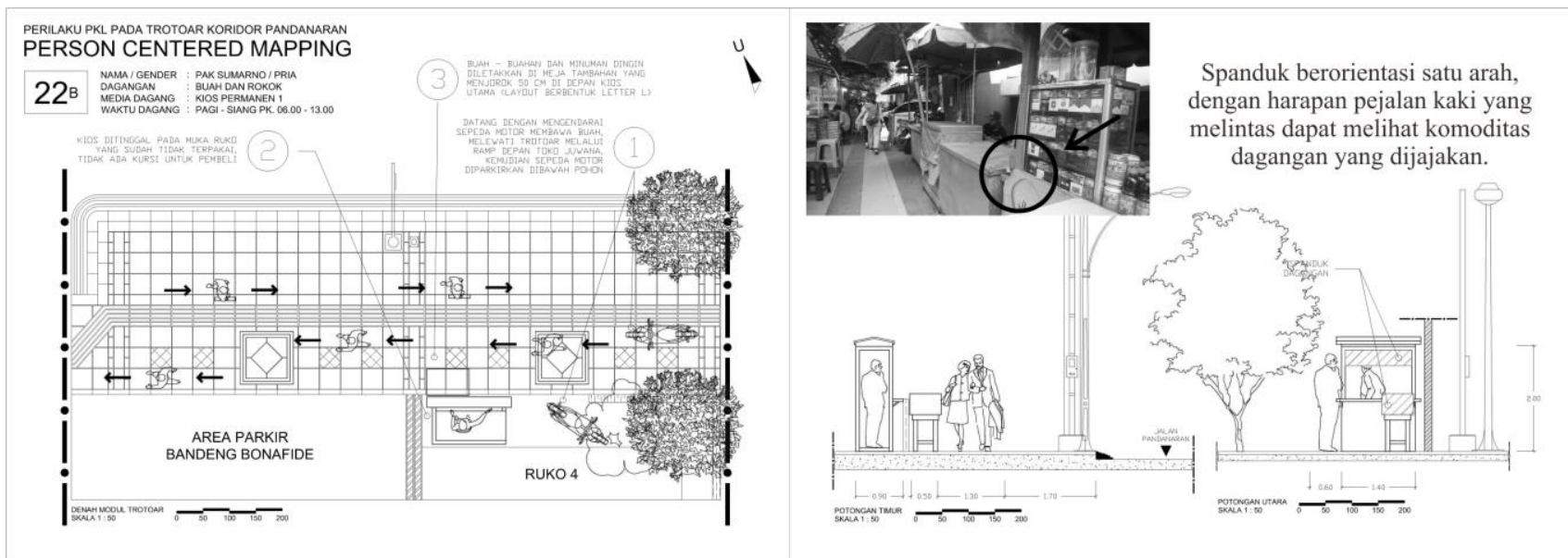

Gambar 14. Person Centered Mapping Adaptabilitas Manfaat PKL Lain

Sumber: Analisa Penulis, 2020

\section{Hasil Temuan}

Atribut visibilitas menyangkut pemilihan lokasi berbanding lurus dengan orientasi arah hadap spanduk dagangan. PKL yang berdagang di tepian jalan memasang spanduk yang berorientasi ke segala arah, agar dagangan terlihat oleh pengendara kendaraan dan pejalan kaki yang lewat. Sementara PKL yang memilih berdagang di muka toko karena lapak yang tersisa hanya disitu, memilih memasang spanduk dengan orientasi satu arah yakni kepada pejalan kaki. Akan tetapi terkadang PKL yang ada di muka toko membuat banner tambahan yang diletakkan pada tiang listrik, JPO, dan separator (objek propertis). Usaha ini bertujuan agar pengendara masih bisa melihat keberadaan mereka.

Atribut kenyamanan menyangkut keberadaan JPO dan vegetasi pohon digunakan hampir sebagian besar untuk media spanduk dagangan dan pernaungan. Banyak spanduk atau banner yang tertempel disitu, meskipun letak PKL lebih jauh 10 meter.

Atribut adaptabilitas menyangkut keberadaan tiang listrik sebagian besar digunakan sama seperti JPO dan pohon yakni untuk spanduk dagangan. Sementara keberadaan PKL lain dijadikan patokan dan dianggap tidak mengganggu. 
Dari tiga zona dagang zona $\mathrm{A}, \mathrm{B}$, dan $\mathrm{C}$ masing - masing memiliki karakteristik pedagangnya. Zona A dengan 4 PKL seluruhnya berdagang di muka toko dengan alasan lebih mengutamakan atribut kenyamanan yakni pernaungan. Zona B dengan 10 PKL 5 PKL berdagang di tepi jalan, sedangkan 5 sisanya berdagang di muka toko dengan mengedepankan atribut kenyamanan pernaungan. Sementara zona C dengan 19 PKL sebagian besar memilih berdagang di tepi jalan, PKL yang berdagang di muka toko beralasan lebih baik berdagang di muka toko zona $\mathrm{C}$ daripada zona $\mathrm{A}$ dan B (meskipun di pinggir jalan), karena zona $\mathrm{C}$ adalah area ramai dengan activity support berupa pusat oleh - oleh. Maka dari itu PKL zona $\mathrm{C}$ yang berada di muka toko mensiasati visibilitas view to site dengan spanduk yang diletakkan pada street furniture sekitar lapak serta mengandalkan PKL yang berada didepannya untuk ikut mempromosikan.

\section{Kesimpulan}

Dapat disimpulkan bahwa perilaku yang ditunjukkan oleh PKL di trotoar koridor Pandanaran terkait dengan persepsi atribut visibilitas, terutama dalam hal pemilihan lokasi dagang. Didalam pemilihan lokasi dagang, PKL mengetahui zona mana yang ramai tetapi visibilitas view to site nya rendah dan zona yang sepi akan tetapi view to site nya tinggi. Sebagian besar mengutamakan visibilitas, sementara yang lain lebih mengutamakan kenyamanan atau adaptabilitas. PKL dengan eksisting lapak kurang terlihat dari jalan raya terutama zona $\mathrm{C}$ yang lebih mementingkan keramaian, menata spanduk atau banner pada street furniture yang ada, sehingga street furniture itu sendiri memiliki kekuatan propertis bagi PKL yang memanfaatkannya. Sementara PKL yang berdagang di zona A dan B lebih mementingkan kenyamanan, sehingga visibilitas tidak dianggap paling penting karena keberadaan mereka sudah diketahui dan view to site nya tinggi.

\section{Daftar Pustaka}

Archea, J. (1977). The Place of Architectural Factors in Behavioral Theories of Privacy. Journal of Social Issues, 33(3), 116-137.

Atkinson, R. L. (1983). The Hidden Dimention. New York: New York Doubleday.

Azwar, S. (2002). Reliabilitas dan Validitas Data. Yogyakarta: Pustaka Belajar.

Bell, P. A., Fisher, J. D., \& Loomis, R. J. (2001). Environmental Psychology. Philadelphia: WB Saunders Company.

Grigg, N. S. (1988). Infrastructure, Engineering, and Management. Australia: John Wiley \& Sons.

Haryadi, \& Setiawan, B. (2010). Arsitektur, Lingkungan dan Perilaku. Yogyakarta: Gadjah Mada University Press.

Laurens, J. M. (2004). Arsitektur dan Perilaku Manusia. Jakarta: Grasindo.

McGee, T. G., \& Yeung, Y. M. (1977). Hawkers In South East Asian Cities: Planning for The Bazaar Economy. Ottawa: International Development Research Center.
Sommer, B., \& Sommer, R. (1991). A Practical Guide To Behavioral Research Tools and Techniques. New York: Oxford University Press.

Wardianto, G., Budihardjo, E., \& Prianto, E. (2012). TUNTUTAN ATRIBUT PERSEPSI PEJALAN KAKI PADA PENGGUNAAN JEMBATAN PENYEBERANGAN DI JATINGALEH SEMARANG. Dinamika TEKNIK SIPIL, 12(2), 194-200.

Weisman, G. D. (1981). Modelling Environtment Behavior System. A Brief Note. Journal of ManEnvironment Relations, 32-41.

Widjajanti, R. (2009). Karakteristik Aktivitas Pedagang Kaki Lima pada Kawasan Komersial di Pusat Kota. Teknik, 30(3), 162-171.

Windley, P. G., \& Scheidt-, R. J. (1980). THE WELL BEING OF OLDER PERSONS IN SMALL RURAL TOWNS: A TOWN PANEL APPROACH. Educational Gerontology, 5, 355373. https://doi.org/10.1080/0360127800050403 